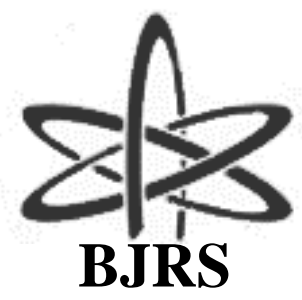
BRAZILIAN JOURNAL
$\mathrm{OF}$
RADIATION SCIENCES
09-01A (2021) 01-15

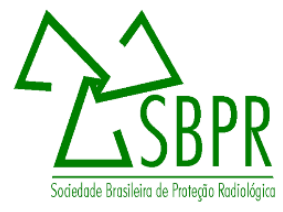

\title{
Study of cesium sorption by a Brazilian bentonite
}

\author{
Santos $^{\mathrm{a}}$ D. M. M., Tello ${ }^{\mathrm{b}}$ C. C. O. \\ ${ }^{a, b}$ Centro de Desenvolvimento da Tecnologia Nuclear, 31270-901, Belo Horizonte, MG, Brazil \\ amarymarchezini@gmail.com; ${ }^{b}$ tellocc@cdtn.br
}

\begin{abstract}
Engineered and natural barriers compose the disposal system of near surface repository to store low and intermediate level radioactive wastes. Waterproofing barriers are constituted of clays, such as the bentonite, in order to avoid or to limit the release of radionuclides into the environment until their decay at a safe level of radiation to humans and the environment. Characteristics such as high cation exchange capacity, high adsorption capacity and high sealing capacity, are taken into consideration for choosing this material. The migration of radionuclides through protection barriers can occur in a variety of ways, such as surface water infiltration, groundwater intrusion, among others. Diffusion is the process which governs the contaminant transport through soil barriers. Adsorption is one of the processes that could be considered in the diffusion mechanism, and sorption isotherms are obtained from values measured in the batch-adsorption experiments. Therefore, such experiments were carried out in order to estimate the cesium sorption by the bentonite. The quantitative analysis was performed using atomic absorption and the energy dispersive $\mathrm{X}$-ray fluorescence spectrometry. With the purpose to calculate the true value of cesium sorption, a mass-balance was made considering all the steps of the batch experiment, and it was found a $6 \%$ loss in the whole process. The quantity of cesium sorbed by the bentonite was $66.7 \mathrm{mg}^{-1}$. At the moment, eight additional experiments are being performed, using solutions with different cesium concentrations, leading to all the necessary data for the isotherm.
\end{abstract}

Keywords: bentonite, cesium, sorption, multiple barriers. 


\section{INTRODUCTION}

The management of radioactive waste aims to ensure the safe storage of such wastes, in order to protect the environment and humans. During the management of these wastes, storage can be done in different types of deposits, and the final storage is carried out in repositories. Low and intermediate level radioactive wastes are stored in near surface repository $[1,2,3]$.

The near surface repository is used in several countries and, in order to assure public safety and confidence, the institutional controls is carried out after the end of the operation stage of the repository. The operational phase of the repository takes 60 years and the post-closure phase lasts for 300 years $[4,5,6]$. The repository is formed by the deposition areas and the support facilities. Deposition areas consist of several barriers in order to avoid or to limit the release of radionuclides into the environment until their decay at a safe level of radiation to humans and the environment [7].

These barriers are composed of layers in the bottom of the deposition, the filling layer and the concrete structures. In addition, after closing the concrete structures, there is a final coverage of the deposition area. The barriers can be made of various materials, such as clays, which are studied for the filling and covering layers [7]. Bentonite is a clay composed mainly by minerals of the montmorillonite group and is characterized by high sorption capacity, low hydraulic conductivity and low diffusion coefficient $[7,8,9,10]$.

The specific surface area is defined as the ratio of the total surface area per unit weight of clay and expressed in $\mathrm{m}^{2} \cdot \mathrm{g}^{-1}$. Such property influences in the sorption process [11], being one of the important characteristics when choosing the bentonite as a waterproofing barrier material.

The release and migration of radionuclides through the repository protection barriers can occur in a variety of ways, such as surface water infiltration, groundwater intrusion, degradation of the deposition system in cases of unforeseen accidents or interference, among others. The behavior of these radionuclides in the environment will depend on the chemical and physical interactions with the soil [12]. The mechanisms of interaction between the radionuclide and the soil considered important are precipitation/dissolution and adsorption/desorption [13]. 
An adsorption curve, or isotherm, is the graphical representation of the amount of solute adsorbed by an adsorbent as a function of the equilibrium concentration of such solute. This ratio is quantitatively defined by an isothermal adsorption equation, which is then statistically applied to the sorption data. There are several equations that can describe these data, but the Freundlich and Langmuir isotherms are the ones most commonly used [14].

The retardation factor is an empirical parameter that describes the interaction between the contaminant and the soil in transport models, and includes processes such as adsorption and precipitation. This parameter uses the partition coefficient $-\mathrm{K}_{\mathrm{d}}-$ that can estimate the sorption potential of a solute (contaminant) in contact with the sorbent (soil), i.e., the partition of the solute between the solid and liquid phases [13]. The value of $\mathrm{K}_{\mathrm{d}}$ can be determined experimentally in the laboratory by means of isothermal analyzes obtained in batch-adsorption experiments and it is only valid if it obtains a linear behavior sorption isotherm [13]. The isotherms do not always present linearity, but with an adjustment of the curve obtained experimentally it is possible to approximate the $K_{d}$ using the Freundlich or Langmuir isotherms models [15].

\section{MATERIALS AND METHODS}

The material used for the tests was the sodium bentonite constituted of $67.2 \%$ montmorillonite, available in Brazilian territory [16]. The experiments were carried out in the Cementation Laboratory - LABCIM -, Chemical Analysis Laboratory - LAQ -, and Nuclear Fuel Laboratory LABCON - of the Nuclear Technology Development Center - CDTN. Figure 1 summarizes the methodology used in the experiments.

Figure 1: Diagram of the experiments.

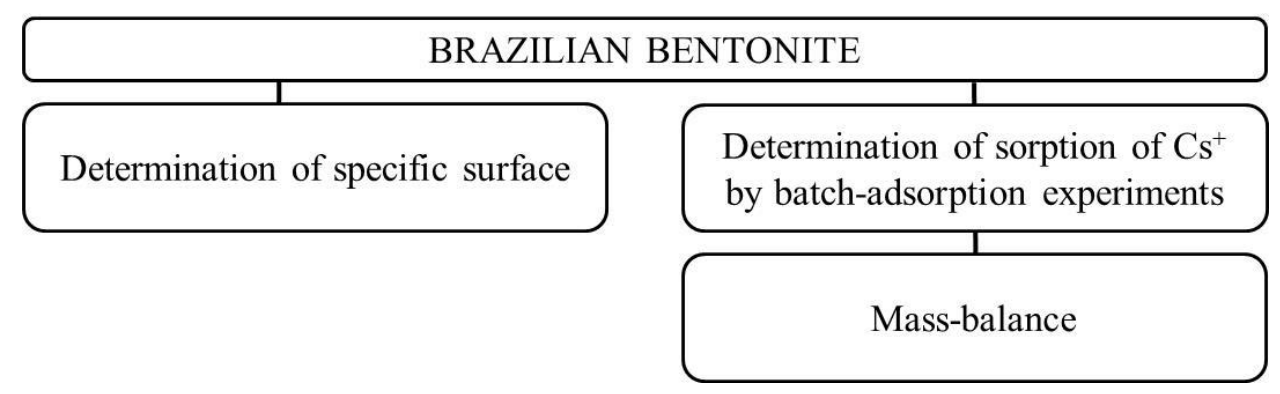




\subsection{Determination of the specific surface}

The specific surface was performed by nitrogen gas adsorption using automated physical sorption that yield adsorption and desorption equilibrium data. The specific area considers the gas molar volume, the area occupied by the gas and the formed monolayer. The specific surface is the ratio between the superficial area and the clay mass.

Initially, two grams of the bentonite were subjected to a two-hour degassing process by vacuum heating at a temperature of $100{ }^{\circ} \mathrm{C}$ in order to clean the sample surface. For the measurement of the specific surface it is necessary that the whole surface of the clay is covered by a monolayer of nitrogen. Then, additions of $\mathrm{N}_{2}$ gas were made at a temperature of $-196{ }^{\circ} \mathrm{C}$, which were adsorbed through condensation on the surface and in the pores of the bentonite. The value of the specific surface were obtained through the NOVADRP program, which uses the Multi-Bet (BrunauerEmmett-Teller - BET equation) (Equation 1) to obtain the parameters related to specific surface $[17,18]$.

$$
\frac{P}{V\left(P_{0}-P\right)}=\frac{1}{V_{m} c}+\frac{\left[\frac{(c-1)}{V_{m} c}\right] P}{P_{0}}
$$

in which $P$ is the vapor pressure of the gas, $P_{0}$ is the saturation vapor pressure of the adsorbate, $V$ is the volume of adsorbed gas, $V_{m}$ is the amount of gas corresponding to the monolayer of the adsorbed molecules (volume of $\mathrm{N}_{2}$ ), and $c$ is the constant that relates the heat of condensation to the adsorption heat of the first layer.

\subsection{Determination of sorption of $\mathrm{Cs}^{+}$by batch-adsorption experiments}

This assay is in accordance with the method described in EPA 530 [14], which is performed in three steps: determination of the ratio clay:solution, determination of the equilibrium time, and the construction of the sorption curves. In all the three steps, the temperature, stirring and $\mathrm{pH}$ were controlled. These systems (clay:solution ratio) were under constant agitation (29 $\pm 2 \mathrm{rpm}$ ), at a temperature of $22 \pm 3^{\circ} \mathrm{C}$. 
The equipment used for the sample shaking was the rotary shaker available in the LABCIM/CDTN (Figure 2), which was built according to the criteria established in the National Bureau of Standards - NBS [14].

Figure 2: Rotary shaker used in the batch-adsorption test.

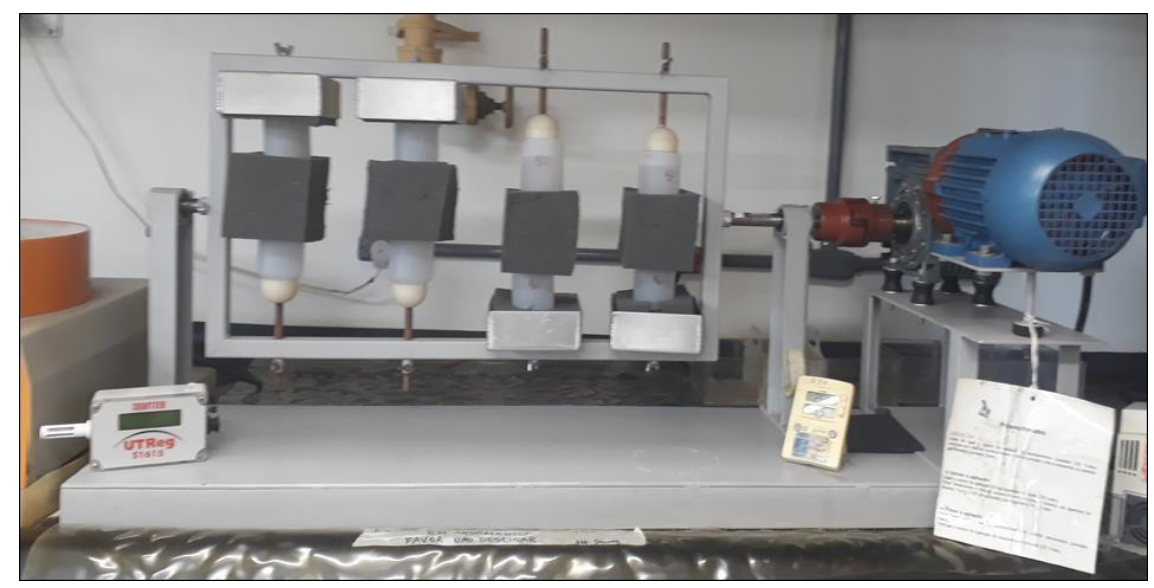

\subsubsection{First step of the test: determination of the ratio clay:solution}

This step consists of selecting the best ratio clay:solution to be used for the construction of the sorption isotherms.

The stock solution used contained 0.74 g. $\mathrm{L}^{-1}$ of inactive cesium. For each ratio, a blank containing only the cesium solution without contact with the clay was prepared, agitated and filtered under the same conditions as the ratio tests. The bentonite used in the ratios clay:solution contains $9.97 \%$ of moisture. The volume of the solution was $200 \mathrm{~mL}$. For each of them, the values of the true clay masses $\left(m_{T}\right)$ have to be calculated. For example, for the 1:20 ratio, in $200 \mathrm{~mL}$ of solution, $10 \mathrm{~g}$ of clay $\left(m_{R}\right)$ would be required. However, since this clay has $9.97 \%$ of moisture content $(\% U), 11 \mathrm{~g}$ was required for the test (Equation 2).

$$
m_{T}=m_{R}\left[1+\frac{\% U}{100}\right]
$$

Table 1 shows the values of the clay:solution ratios tested. 
Table 1: Mass calculated for the ratios prepared in the first step.

\begin{tabular}{ccc}
\hline $\begin{array}{c}\text { Ratio clay:solution } \\
(\mathbf{g}: \mathbf{m} \mathbf{L})\end{array}$ & $\begin{array}{c}\text { Real clay mass } \\
\left(\boldsymbol{m}_{\boldsymbol{R}}\right)(\mathbf{g})\end{array}$ & $\begin{array}{c}\text { True clay mass } \\
\left(\boldsymbol{m}_{\boldsymbol{T}}\right)(\mathbf{g})\end{array}$ \\
\hline $1: 20$ & 10.0 & 11.0 \\
$1: 40$ & 5.0 & 5.5 \\
$1: 60$ & 3.3 & 3.7 \\
$1: 100$ & 2.0 & 2.2 \\
$1: 200$ & 1.0 & 1.1 \\
$1: 500$ & 0.4 & 0.4 \\
\hline
\end{tabular}

The best ratio is the one whose sorption capacity $(\% A)$ is between 10 and $30 \%$. After shaking for $24 \pm 0.5 \mathrm{~h}$, the solid phase was separated from the liquid phase by vacuum filtration using a $0.45-\mu \mathrm{m}$ pore-size membrane filter. The filtrate of each ratio was analyzed by atomic absorption in the LAQ / CDTN to determine the concentration of $\mathrm{Cs}^{+}(C)$. The concentration of cesium in the blank $\left(C_{B}\right)$ and the initial $\left(C_{0}\right)$ samples were also determined. For the calculation of the adsorbed percentage $(\% A)$, the Equation 3 was used.

$$
\% A=\left(\frac{C_{0}-C}{C_{0}}\right) \times 100
$$

\subsubsection{Second step of the test: determination of the equilibrium time}

In this step, the ideal equilibrium time for the batch test was determined. The ratio selected in the first step, with its respective blank, was placed under agitation at different times of contact (1, 24, 48 and 72 hours). After each time interval, the clay-solution systems were removed from the shaker and filtered for the separation of phases by vacuum filtration. In the end of the filtration, the samples were sent for the determination of the $\mathrm{Cs}^{+}$concentration by atomic absorption analysis.

Then, for each time interval, the concentration variation $-\% \Delta C-$ between the solute in the initial $t_{1}\left(C_{1}\right)$ and final time $t_{2}\left(C_{2}\right)$ of each agitation was calculated using the Equation 4 . The stirring time chosen is the one in which the concentration variation in the solute is equal to or less than $5 \%$ for the 24 -hour interval, i.e., until the concentration is practically stable. 


$$
\% \Delta C=\left(\frac{C_{1}-C_{2}}{C_{1}}\right) \times 100
$$

The ratio clay:solution 1:500, selected in the previous step, was used. For the following contact times: $1,24,48$ and $72 \mathrm{~h}$, the temperature was controlled at around $24^{\circ} \mathrm{C}$, rotation of $29 \pm 2 \mathrm{rpm}$, and the $\mathrm{pH}$ remained between 6 and 7 .

\subsubsection{Third step of the test: sorption isotherm by constant ratio method}

The isotherm will be plotted by the constant ratio method, where the concentration of the sorbent (clay) is constant, but the concentration of the solute (cesium) varies. The ratio clay:solution is the one selected previously in the first step and the equilibrium time is the one selected in the second step. According to the EPA 530 [14], at least eight dilutions are recommended for the construction of the adsorption curve. Table 2 shows the initial concentrations to be prepared for each dilution.

The clay-solution systems are placed on the rotary shaker for the time determined in the second step. After stirring, the phases are separated by vacuum filtration and the filtrate is analyzed by atomic absorption.

Table 2: Initial concentrations $\left(C_{0}\right)$ of the solutions for the third step.

\begin{tabular}{ccc}
\hline Sample code & Solution number & $\begin{array}{c}\text { Concentration of the } \mathbf{C s}^{+} \text {solution to be prepared } \\
\left(\boldsymbol{\mu g . \mathbf { L } ^ { - 1 } )}\right.\end{array}$ \\
\hline 3R6AD1 & 1 & $7.40 \mathrm{E} 05$ \\
3R6AD2 & 2 & $3.70 \mathrm{E} 05$ \\
3R6AD3 & 3 & $1.85 \mathrm{E} 05$ \\
3R6AD4 & 4 & $1.00 \mathrm{E} 05$ \\
3R6AD5 & 5 & $7.00 \mathrm{E} 04$ \\
3R6AD6 & 6 & $4.00 \mathrm{E} 04$ \\
3R6AD7 & 7 & $2.00 \mathrm{E} 04$ \\
3R6AD8 & 8 & $1.00 \mathrm{E} 04$ \\
\hline
\end{tabular}




\subsection{Mass-balance of batch-adsorption experiment}

In order to calculate the true value of the cesium sorption, a mass balance was made considering all the stages of the experiment under the following conditions:

- Ratio clay:solution 1:500;

- Agitation time $24 \mathrm{~h}$;

- Rotation $29 \pm 2$ rpm;

- Filtration through vacuum using $0.45-\mu \mathrm{m}$ pore-size membrane filter;

- Analysis of $\mathrm{Cs}^{+}$using the X-ray Fluorescence Spectrometer by dispersive energy.

For the mass-balance, in addition to the steps of the batch equilibrium test, an acid leaching step was added in order to determine the presence of cesium not sorbed by the clay. This leaching was done with a $10 \%$ v/v solution of $\mathrm{HNO}_{3}$.

The X-ray Fluorescence Spectrometer by dispersive energy available in LAQ/CDTN was used for the mass-balance. First, it was determined the amount of $\mathrm{Cs}^{+}$in the initial solution without contact with the bentonite. Then, the amounts of $\mathrm{Cs}^{+}$in the various phases of the test (systems 0,1 and 2) and the amount of $\mathrm{Cs}^{+}$sorbed by the clay (system 3), were determined in order to perform the mass-balance.

\section{RESULTS AND DISCUSSION}

The parameters obtained in the batch-adsorption experiment for the isotherm curve determination are shows in Table 3.

Table 3: Parameters obtained for the isotherm curve.

\begin{tabular}{lc}
\hline Criterias & Parameters \\
\hline sorption capacity (\%A) & 36.4 \\
clay:solution ratio & $1: 500$ \\
equilibrium time (hours) & 48 \\
\hline
\end{tabular}


For the 1:100, 1:200 and 1:500 ratios, the $\mathrm{pH}$ measured was between 6 and 7, and for the ratios 1:20, 1:40 and 1:60, the $\mathrm{pH}$ was between 8 and 9. When sorption of inorganic cations occurs in a medium with a high $\mathrm{pH}$ value, there is an increase in their sorption capacity. The sorption capacity $-\% \mathrm{~A}$ - was calculated according to the Equation 3. The ratio 1:500 was chosen because it presented a sorption capacity value around the recommended limit. Table 4 shows the concentrations of $\mathrm{Cs}^{+}$ for each ratio obtained in the atomic absorption analysis.

Table 4: Concentration data of Cs+ and \%A for each ratio in the first step.

\begin{tabular}{cccc}
\hline Sample code & $\begin{array}{c}\text { Ratio clay:solution } \\
(\mathbf{g}: \mathbf{m L})\end{array}$ & $\begin{array}{c}\text { Concentration of the } \\
\mathbf{C s}^{+}\left(\boldsymbol{\mu g . \mathbf { L } ^ { - 1 } )}\right.\end{array}$ & $\begin{array}{c}\text { Sorption capacity } \\
(\boldsymbol{\%} \mathbf{A})\end{array}$ \\
\hline 1R1A & $1: 20$ & 29.400 & 95.6 \\
1R2A & $1: 40$ & 29.600 & 95.5 \\
1R3A & $1: 60$ & 53.300 & 92.0 \\
1R4A & $1: 100$ & 152.000 & 77.1 \\
1R5A & $1: 200$ & 344.200 & 48.2 \\
1R6A & $1: 500$ & 403.060 & 36.4 \\
\hline
\end{tabular}

For the determination of the equilibrium time, the samples were filtered and analyzed by atomic absorption. With the results, a curve relating cesium concentration in equilibrium versus contact time was made. Then, the concentration variation was calculated (Figure 3). In this way, the ideal equilibrium time chosen was of 48 hours once the variation in the concentration in the solute was less than $5 \%$ and presenting practically stable behavior in an interval of 24 hours.

Figure 3: Determination of the equilibrium time for the batch equilibrium test.

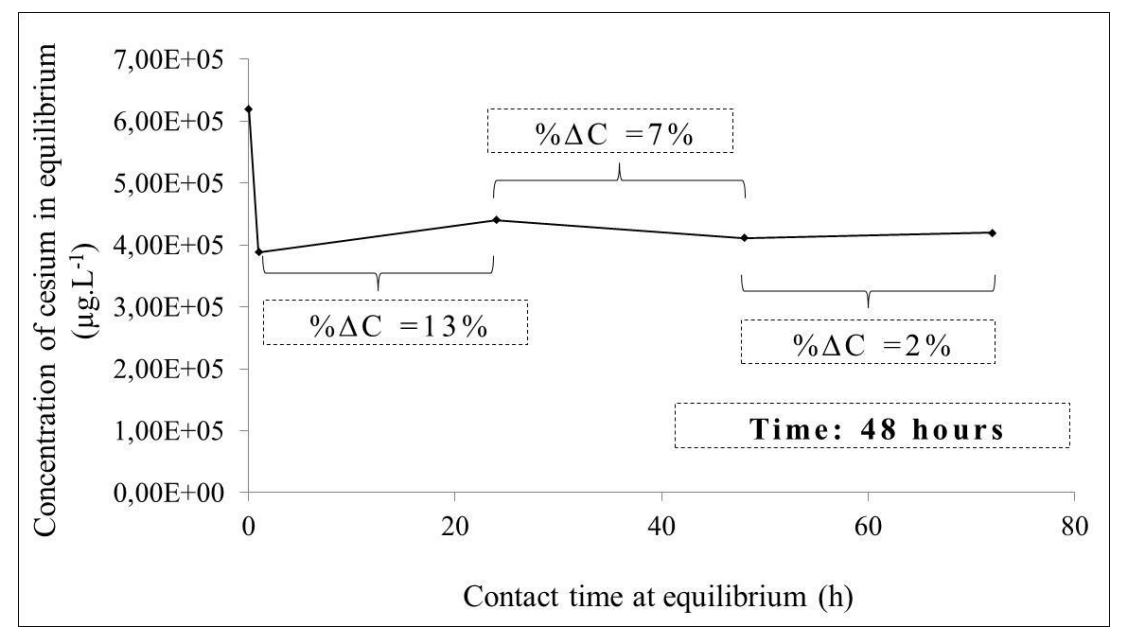


The step for the construction of the adsorption curve (third step) is currently in progress, but with the results obtained until moment evidence that the bentonite under study is a material recommended for use as natural barriers of the Brazilian repository. Furthermore, the specific surface of the bentonite was calculated and the value found was $80.49 \mathrm{~m}^{2} \cdot \mathrm{g}^{-1}$. This value imply that the material has a high adsorption capacity.

\subsection{Mass-balance results}

The flowchart with the steps of the batch equilibrium test and the appropriate masses used in the mass-balance is shown in Figure 4, where the concentrations of $\mathrm{Cs}^{+}$considered in each step of the test are also specified.

Figure 4: Scheme of the stages considered in the mass-balance with the results for each one.

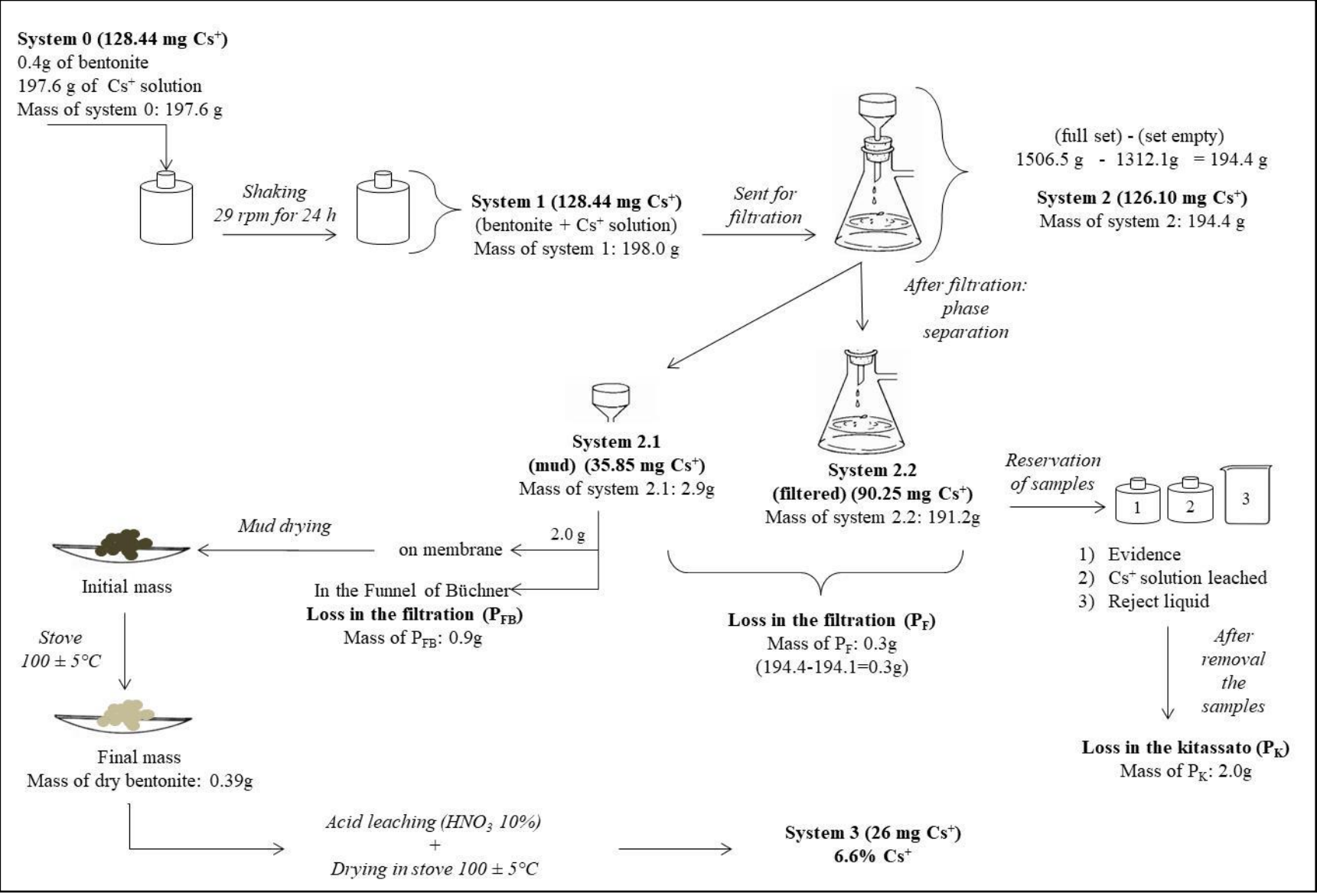


Then, for the mass-balance, the following amounts of $\mathrm{Cs}^{+}$were considered (Table 5).

Table 5: Quantities of $\mathrm{Cs}^{+}$used for the mass-balance.

\begin{tabular}{cc}
\hline System & Amount of Cs $^{+}(\mathbf{m g})$ \\
\hline System 0 & 128.44 \\
System 1 & 128.44 \\
System 2 & 126.10 \\
System 2.1 & $35.85^{*}$ \\
System 2.2 & 90.25 \\
System 3 & 26.0 \\
*value calculated by the difference between systems 2 and 2.2
\end{tabular}

For the mass-balance, system 2 was considered as the initial condition for the sorption process, named $\mathrm{S}_{2 \mathrm{~B}}$, which refers to the value calculated in the balance. The other systems and the losses during the test were considered according to the Equation 5.

$$
S_{2 B}=\sum S_{2.2}+S_{3}+\left(P_{K}+P_{F}+P_{F B}\right)
$$

The losses were denominated as $P$, with $P_{K}$ being the amount retained in the kitassato, $P_{F}$ the mass lost in the filtration, and $P_{F B}$ the retained mass in the Büchner funnel. The masses lost were summed $(3.2 \mathrm{~g})$ and related to the amount of $\mathrm{Cs}^{+}$of system 2 , thus obtaining $2.08 \mathrm{mg}$ of $\mathrm{Cs}^{+}$lost during the process and the sum for $S_{2 B}$ was $118.33 \mathrm{mg}$.

For the closure of the mass-balance, the amount of $\mathrm{Cs}^{+}$obtained in $S_{2 B}$ is expected to approximate the amount of $\mathrm{Cs}^{+}$obtained for system $2\left(S_{2}\right)$. Therefore, there is a loss of $7.77 \mathrm{mg}$ throughout the sorption process, which represents $6 \%$ of the amount considered as the initial condition.

\section{CONCLUSION}

The high specific surface of the bentonite indicates the possibility of obtaining a large number of sorption of the material. With the best ratio clay:solution, the minimum amount of cesium and 
bentonite (solute:sorbent) is determined to be an ideal sorption. The contact time of 48 hours was selected because of a concentration variation of less than 5\%, as indicated in the methodology used. In the third step of the batch-adsorption experiment, the preparation of the diluted samples will be done, according to Table 3 and the batch-adsorption experiment is performed so that the isotherms are made in order to obtain an approximation of $\mathrm{K}_{\mathrm{d}}$. Considering that during batch-adsorption experiment there are several steps in which there may be losses of material in the transfers, the value of $6 \%$ is considered relatively small. For future work, it is suggested that a mass balance of some dilute cesium solutions should be checked, thus verifying the linearity of the sorption at various concentrations of solute. Also, the same methodology should be used with another type of bentonite. Such assays are being developed in CDTN. 


\section{ACKNOWLEDGMENT}

This research project is supported by the following Brazilian institutions: Nuclear Technology Development Center - CDTN -, National Nuclear Energy Commission - CNEN. I thank Dra. Clédola Cássia for the support and teaching, the technical team of CDTN for the support in performing the tests, and the institution CNEN for the scholarship.

\section{REFERENCES}

[1] CNEN - Comissão Nacional de Energia Nuclear. Seleção e escolha de locais para depósitos de rejeitos radioativos. Resolução 014/89, CNEN-NE-6.06. Rio de Janeiro, Rio de Janeiro, Brazil. 1990. Available at: <http://appasp.cnen.gov.br/seguranca/normas/pdf/Nrm606.pdf>. Last accessed: 25 June 2020.

[2] CNEN - Comissão Nacional de Energia Nuclear. Critérios de aceitação para deposição de rejeitos radioativos de baixo e médio níveis de radiação. Resolução 012/02, CNEN-NN-6.09. Rio de Janeiro, Rio de Janeiro, Brazil. 2002. Available at: <http://appasp.cnen.gov.br/seguranca/normas/pdf/Nrm609.pdf〉. Last accessed: 25 June 2020.

[3] CNEN - Comissão Nacional de Energia Nuclear. Gerência de Rejeitos Radioativos de Baixo e Médio Níveis de Radiação. Resolução 167/14, CNEN NN 8.01. Rio de Janeiro, Rio de Janeiro, Brazil. 2014. Available at: <http://appasp.cnen.gov.br/seguranca/normas/pdf/Nrm801.pdf〉. Last accessed: 25 June 2020.

[4] IAEA - International Atomic Energy Agency. Scientific and technical basis for the near surface disposal of low and intermediate level waste. Technical reports series, No. 412, Vienna: IAEA, 2002. 67p.

[5] IAEA - International Atomic Energy Agency. Classification of radioactive waste. General Safety Guide series, No. GSG-1, Vienna: IAEA, 2009. 48p.

[6] IAEA - International Atomic Energy Agency. Selection of Technical Solutions for the Management of Radioactive Waste. TECDOC-1817, Vienna. IAEA, 2017. 112p. 
[7] IAEA - International Atomic Energy Agency. Performance of engineered barrier materials in near surface disposal facilities for radioactive waste. TECDOC-1255, Vienna. IAEA, 2001. 56p.

[8] BOHNHOFF G. L.; SHACKELFORD C. D. Hydraulic Conductivity of Chemically Modified Bentonites for Containment Barriers, In: 7th INTERNATIONAL CONGRESS ON ENVIRONMENTAL GEOTECHNICS, 2014, Austrália. Annals...Austrália: International Society of Soil Mechanics and Geotechnical Engineering, 2014, pp.440.

[9] TELLO, C.C.O. Efetividades das Bentonitas na retenção de césio em produtos de Rejeitos Cimentados, Tese de Doutorado em Engenharia Química, Campinas: Faculdade de Engenharia Química/Universidade Estadual de Campinas, Brazil, 2001. 167p.

[10] SKB - Svensk Kärnbränslehantering AB. Models for Diffusion in Compacted Bentonite. TR-15-06, Estocolmo, Suécia. SKB, 2016. 52p.

[11] BRADY N. C.; WEIL R. R. Elementos da natureza e propriedades dos solos, $3^{\text {rd }}$ ed. Porto Alegre, Brazil : Bookman (2012).

[12] OLSZEWSKA W.; MISKIEWICZ A.; ZAKRZEWSKA-KOLTUNIEWICZ G.; LANKOF L.; PAJAK L. Multibarrier system preventing migration of radionuclides from radioactive waste repository. Nukleonika, v. 60, n. 3, p. 557-563, 2015.

[13] EPA - Environmental Protection Agency. Understanding Variation in Partition Coefficient, $K_{d}$, values. Volume 1: The $K_{d}$ Model, Methods of Measurement, and Application of Chemical Reaction Codes. EPA 402-R-99-004A, Washington D.C, United States, EPA, 1999. 212p.

[14] EPA - Environmental Protection Agency. Technical Resource Document: Batch-type Procedures for estimating soil adsorption of chemical. EPA 530 SW-87-006-F, Washington D.C, United States, EPA, 1992. 116p.

[15] SOARES, M. R. Coeficiente de distribuição $\left(K_{\mathbf{D}}\right)$ de metais pesados em solos do estado de São Paulo. Tese de Doutorado em Agronomia: solos e nutrição de plantas da Escola Superior de Agricultura "Luiz de Queiroz", Universidade de São Paulo, Piracicaba, São Paulo, Brazil, 2004. 214p. 
[16] ANM - Agência Nacional de Mineração. Sumário Mineral Brasileiro 2018. Brasília, Distrito Federal, Brazil. 2020. Available at: <http://www.anm.gov.br/dnpm/publicacoes/serieestatisticas-e-economia-mineral/sumario-mineral/pasta-sumario-brasileiro-mineral-2018/ bentonita_sm_2018>. Last accessed: 27 June 2020.

[17] TEIXEIRA V.G.; COUTINHO F. .M. B.; GOMES A. S. Principais métodos de caracterização da porosidade de resinas à base de divinilbenzeno. Química Nova, v. 24, n. 6, p. 808-818, 2001.

[18] GREGG S. J.; SING K. S. W. Adsorption, Surface Area and Porosity, $2^{\text {rd }}$ ed., London: Academic Press, 1982. 